\title{
Experience of Percutaneus Kidney Biopsy from a Tertiary Care Center of Pakistan
}

\author{
Ali Absar ${ }^{1}$, Naila Asif ${ }^{2}$, Quratulain Khan1, Waqar Kashif ${ }^{1}$ \\ ${ }^{1}$ Aga Khan University Hospital, Karachi, Pakistan \\ ${ }^{2}$ Liaquat National Hospital, Karachi, Pakistan \\ Email: *draliabsar@yahoo.com
}

Received 24 May 2015; accepted 19 June 2015; published 23 June 2015

Copyright (C) 2015 by authors and Scientific Research Publishing Inc.

This work is licensed under the Creative Commons Attribution International License (CC BY).

http://creativecommons.org/licenses/by/4.0/

(c) (i) Open Access

\begin{abstract}
Background: Kidney biopsy is one of the most important tools in the assessment of kidney disease. Knowing the histopathology is important for immediate clinical management. It helps in predicting the long term prognosis and in planning for prevention of chronic kidney disease. Methods: This is a cross section study of percutaneus biopsies of the native kidneys of patients, who presented to the Aga Khan University Hospital Karachi Pakistan, over ten year period from 2003 to 2012. Age range was 16 to 77 years. Results: Total number of 435 biopsies were included in the study. The most common histopathological findings, regardless of the indication of biopsy were Tubulo Interstitial Nephritis in 15 percent, followed by Membranous Nephropathy in 12 percent, Focal Segmental Glomerulosclerosis in 8 percent and Membrano Proliferative Glomerulonephritis also in 8 percent. Conclusion: This study will help in better understanding the spectrum of renal disease in Pakistan. It will guide the clinician in the management and provide a data base or a starting point for the researchers for conducting the controlled and population base studies.
\end{abstract}

\section{Keywords}

Kidney, Biopsy, Pakistan

\section{Introduction}

Kidney biopsy is one of the essential components of the work up needed for the evaluation of the kidney disease. In an appropriate setting, it is the key investigation necessary to reach the correct diagnosis, to predict the clinical course and to institute the right treatment [1].

The common indications of biopsy of the native kidney include unexplained rise in serum creatinine, unex-

"Corresponding author.

How to cite this paper: Absar, A., Asif, N., Khan, Q. and Kashif, W. (2015) Experience of Percutaneus Kidney Biopsy from a Tertiary Care Center of Pakistan. Open Journal of Nephrology, 5, 61-66. http://dx.doi.org/10.4236/ojneph.2015.52010 
plained proteinuria with or without hematuria nephrotic syndrome, and in systemic diseases like lupus nephritis for staging purposes. Biopsy of the transplanted kidney is performed most often when there is an acute rise in scrum creatinine suspecting rejection. Kidney biopsy is not indicated in diabetic patients, unless one suspects some other non diabetic pathology. With wide spread use of automatic disposable biopsy gun, the procedure is very safe. However it does not mean to relax the criteria or not to observe the standard precautions for the procedure because complications including death still do occur [2].

With rising incidence and prevalence of chronic kidney disease, now it is even more important to know the exact cause of acute and chronic kidney injury. Early intervention helps in controlling the progression of chronic kidney disease. Planning and rationing of the resources also require specific knowledge of the renal diseases in a given population. Our study will help in defining the pattern of kidney disease in Pakistan particularly in Karachi [3].

There are similar studies done in Pakistan as well as in other parts of the world. The findings of these studies are described in the discussion section latter.

\section{Methods}

This is a cross section study of percutaneus native kidney biopsies of patients presented to Aga Khan University Hospital Karachi Pakistan, over ten years of period from 2003 to 2012.

\subsection{Inclusion Criteria}

Only the biopsies performed in the premises of the Institution were included. Biopsies sent from outside for reading only were not included.

\subsection{Exclusion Criteria}

1) Age less than 16 years;

2) Kidney Transplant;

3) Non-Conclusive Results;

4) Poor samples i.e. glomeruli less than 3.

\subsection{Pre-Biopsy Workup}

Minimal workup included the following:

1) 24-Hours urine protein or spot urine protein/creatinine ratio;

2) Urine Detail Report;

3) Serum Urea and Creatinine;

4) Coagulation Profile;

5) Complete blood Picture (CBC);

6) Renal sonogram.

Additional tests were performed as indicated depending upon the clinical situation.

Biopsies were taken either by a nephrologist or a radiologist under ultrasound or CT scan guidance. Biopsies were read by a well trained and experienced renal histopathologist. Light microscopy included staining with Hematoxylin and Eosin (H \& E), periodic acid Schiff (PAS), Massone's trichrome, and Jones silver methanamine were done. Immunofluorescence staining was also done in all the cases. Electron microscope was not available.

\section{Results}

Total number of 435 biopsies were included in the study.. The age range was 16 to 85 years with mean age of 40 years. There were $58 \%$ male and $42 \%$ female.

The most common histopathology, regardless of the indication of biopsy, was Tubulo Interstitial Nephritis in 67 patients (15\%), followed by Membranous Nephropathy in 55 (12\%) and then Focal Segmental Glomerulosclerosis in 38 (8\%) and Membrano Proliferative Glomerulonephritis in 36 (8\%) of biopsies.

Diabetic Nephropathy was the pathology identified in 29 out of 62 diabetic patients who were subjected to 
biopsy for suspecting non diabetic kidney disease. The pathological pattern of 26 lupus patients included all classes of lupus nephritis. Miscellaneous group includes those diagnosis which were only in one or two in number (Table 1).

\section{Discussion}

There are several kidney biopsy based studies available from Pakistan as well as from other countries. Most of these studies from Pakistan are from single center and usually from a teaching hospital. We are also presenting our experience from a single center, Aga Khan University Hospital Karachi, which is a tertiary care leading teaching institution attached to the medical college and University. In the following paragraphs selected representative studies from Pakistan and from other parts of the world are reviewed.

A survey of the Czech Republic registry of native kidney Biopsies from 1994-2000 included 4000 biopsies. The most frequent diagnosis was IgA nephropathy (34\%) and after that minimal change disease (12\%), non Ig A mesangial proliferative (11\%) membranous (09\%) and tubulo-Interstitial nephritis (4\%) were identified [4].

An analysis of kidney biopsies done over 23 years in Korea included more than 4000 cases. In this study the most common primary glomerular disease was minimal change disease in $26 \%$ followed by IgA Nephropathy in 22\% [5]. An Italian Registry data of more than 14,000 kidney biopsies from 128 centers reported IgA nephropathy, minimal disease and FSGS the highest in the list [6].

Epidemiology study from Romania reviewed 10 year data of more than 600 kidney biopsies. The most common indication for biopsy was nephrotic syndrome. The most common histopathological diagnoses were membranproliferative GN (30\%) and mesangial proliferative GN (29\%) among the primary glomerular diseases [7].

Table 1. Histopathological diagnosis in kidney biopsy.

\begin{tabular}{|c|c|}
\hline Histopathological Diagnosis & Number (Percentage) \\
\hline Tubulo Interstitial Nephritis & $67(15)$ \\
\hline Membranous Nephropathy (MGN) & $55(12)$ \\
\hline Focal Segmental Glomeruloscelosis (FSGS) & $38(8)$ \\
\hline Membrano Proliferative Glomerulonephritis (MPGN) & $36(8)$ \\
\hline Diabetic Glomerulosclerosis & $29(7)$ \\
\hline Lupus Nephritis & $26(6)$ \\
\hline Minimal Change Disease (MCD) & $23(5)$ \\
\hline Acute Tubular Necrosis (ATN) & $18(4)$ \\
\hline Crescentric Glomerulonephritis & $17(4)$ \\
\hline Renal Amyloidosis & $16(4)$ \\
\hline End Stage Renal Disease & $12(3)$ \\
\hline Tumor & $10(2)$ \\
\hline IgA Nephropathy & $8(1.8)$ \\
\hline Post Infectious Glomerulonephritis & $6(1.5)$ \\
\hline Rapidly Progressive Glomerulonephritis & $7(1.7)$ \\
\hline Normal & $7(1.7)$ \\
\hline Acute Cortical Necrosis & $3(0.7)$ \\
\hline Miscellaneous & $20(5)$ \\
\hline Non Conclusive & $37(8)$ \\
\hline Total & $435(100)$ \\
\hline
\end{tabular}


Data from Spain included more than 9000 biopsies. In this study the most common disease was membranous nephropathy among nephrotic patients [8].

Study from United Arab of Emirates presented their data of 490 native kidney biopsies. In this study FSGS was diagnosed in $18 \%$ as compared to chronic proliferative Glomerulonephritis being more common in 36\% [9]. An Indian group reported non IgA mesangial proliferative GN the most common primary glomerular disease in $20 \%$ followed by FSGS in $17 \%$ of patients [10].

Another study from India concluded that membranous nephropathy is the most common primary glomerular disease in elderly more than 60 years of age [11]. A study from Minnesota USA reviewed the data of 195 native kidney biopsies. Most common glomerular disease was Ig A nephropathy (22\%), followed by FSGS (17\%) and then membranous nephropathy (10\%) [12].

A study from New York presented the biopsy review of 132 patients in which primary glomerular disease FSGS was the most common (38\%) and then membranous nephropathy (16\%). This study concluded that the FSGS is emerging as a most common cause of ESRD among primary glomerular diseases patients [13]. Study from San Francisco presented review of 183 native kidney biopsies. Most common diagnoses were IgA nephropathy and FSGS [14].

Jamal Q et al. from Karachi Pakistan reviewed more than 948 renal biopsies from adults. Most common diagnosis were MCD in 29\%, Chronic GN in12 percent [15]. Muzzafar M et al. from Rawalpindi published data of 58 Primary Nephrotic patients. Most common three pathology in kidney biopsy were membrono glomerulonephritis (MPGN) in 32 percent, MCD in 24 percent and mesangial proliferative glomerulonephritis in 21 percent [16].

Osmani MH and Shabnam F published experience of 152 kidney biopsies from Karachi. The most common renal lesions were FSGS in 15\%, Membranous in 13\% and then MCD in 11 percent [17]. Khan AZ et al. from Peshawar reported experience of 130 renal biopsies. Among the patients more than 12 years the most common findings were MPGN in 22\%, membranous GN in 20\% and FSGS in 16 percent [18]. Kazi JI and Mubarak M from Karachi reviewed 350 biopsies from adult patients with nephritic syndrome. In this study the most common diagnosis were FSGS in 36\% followed by membranous GN in 24\% and minimal change in 14 percent [19].

Khan SZ and Ali A published data from Peshawar. Among patients aged 60 years or above with nephrotic syndrome were studied. Most common pathology was minimal change in 40 percent followed by Membranous GN in 21 percent and crescentic GN in 19 percent [20]. Kazi JI and M Mubarak M et al. reported results of 316 kidney biopsies of nephrotic patients from Karachi. Most common pathology was focal segmental Glomerulosclerosis (FSGS) in $40 \%$, then membranous glomerulonephritis (MGN) in $27 \%$ followed by minimal change disease [MCD) in 15 percent [21].

Mubarak M et al. from Karachi reported experience of 1793 adult patients. The most common pathology on renal biopsy was FSGN in 29\%, and membranous in 23\% among primary glomerular disease [11]. Abbas K et al. from Karachi presented the data of nephrotics in all ages. The three most common findings were FSGS, minimal Change and membranous GN [22].

Sabir S et al. reported their experience from Karachi. Sixty biopsies were analyzed. The most common pathologies were FSGS in 26\%, memranous GN in 16\% and IgA Nephropathy in 11 percent among the primary glomerulonaephritis [23]. Choudhary $\mathrm{M}$ et al. from Lahore studied the histological pattern in male patients presented for hematuria, proteinuria and high serum creatinine. Among the adults the most common pathology was c hronic kidney disease and end stage renal disease in 19 percent followed by mesangial proliferative GN and FSGN [24].

There are weaknesses in our study. It is a single center study. Patients may not be true representative of the population. Our study and above mentioned studies altogether is a heterogeneous group and we can not compare one study with the other. However it gives us a data base or at least starting point for the researchers interested in conducting the controlled and population base studies. Our study will help in better understanding the spectrum of renal disease in Pakistan. In addition it will also help the clinician in decision making for the management.

\section{Conclusion}

TubuloInterstitial nephritis, membranous nephropathy, focal segmental glomerulosclerosis, and membrano proliferative glomerulonephritis were the most common histopthological diagnosis in adult patients presented to 
AKU for kidney biopsy. Our data will contribute in better understanding the spectrum of renal disease in Pakistan. It will also guide the clinician in management and possibly in planning the prevention of chronic kidney disease.

\section{References}

[1] Taal, M.W., et al. (2011) The Renal Biopsy. In: Brenner \& Rector’s The Kidney, 9th Edition, Saunders Elsevier, Philadelphia. http://www.clinicalkey.com

[2] Johnson, R.J., et al. (2015) Renal Biopsy. In: Comprehensive Clinical Nephrology, 5th Edition, Saunders Elsevier, Philadelphia.

[3] Jafar, T.H. (2006) The Growing Burden of Chronic Kidney Disease in Pakistan. The New England Journal of Medicine, 354, 995-997. http://dx.doi.org/10.1056/NEJMp058319

[4] Rychlik, I., Jancova, E., Tesar, V., Kolskey, A., Lacha, J., Stegskal, J., et al. (2004) The Czech Registry of Renal Biopsy. Nephrology Dialysis Transplantation, 19, 3040-3049. http://dx.doi.org/10.1093/ndt/gfh521

[5] Choi, I.J., Jeong, H.J., Han, D.S., Lee, J.S., Choi, K.H., Kang, S.W., et al. (2001) Analysis of 4515 Cases of Renal Biopsy in Korea. Yonseri Medical Journal, 42, 247-254. http://dx.doi.org/10.3349/ymj.2001.42.2.247

[6] Gesualdo, L., Di Palma, A.M., Morrone, L.F., Strippoli, G.F. and Schena, F.P. (2004) The Italian Experience of the National Registry of Renal Biopsy. Kidney International, 66, 890-894. http://dx.doi.org/10.1111/j.1523-1755.2004.00831.x

[7] Covic, A., Schiller, A., Carmen, V., Gluhovschi, G., et al. (2006) Epidemiology of Renal Disease in Romania. Nephrology Dialysis Transplantation, 21, 419-424. http://dx.doi.org/10.1093/ndt/gfi207

[8] Rivera, F., Lopez-Gomez, J. and Perez Garcia, R. (2004) Clinicopathological Correlation of Renal Pathology in Spain. Kidney International, 66, 898-904. http://dx.doi.org/10.1111/j.1523-1755.2004.00833.x

[9] Yahya, T.M., Pingle, A., Boobes, Y. and Pingle, S. (1998) Analysis of 490 Kidney Biopsies: Data from United Arab Emirates Renal Disease Registry. Journal of Nephrology, 11, 148-150.

[10] Narasimhan, B., Chacho, B., John, G.T., Korula, A., Kirubakaran, M.G. and Jacob, C.K. (2006) Characterization of Kidney Lesions in Indian Adalts: Towards a Renal Biopsy Registry. Journal of Nephrology, 19, 205-210.

[11] Prakash, J., Singh, A.K. and Sexana, R.K. (2003) Glomerular Diseases in the Elderly in India. International Urology and Nephrology, 35, 283-288. http://dx.doi.org/10.1023/B:UROL.0000020429.14190.5b

[12] Swaminathan, S., Leung, N., Lager, D.J., Melton, L.J., Bergstralh, E.J., Rohlinger, A. and Fervenza, F.C. (2006) Changing Incidence of Glomerular Disease in Olmsted County, Minnesota: A 30-Year Renal Biopsy Study. Clinical Journal of the American Society of Nephrology, 1, 483-487. http://dx.doi.org/10.2215/CJN.00710805

[13] Haas, M., Meehan, S.M., Karrison, T.G. and Spargo, B.H. (1997) Changing Etiologies of Unexplained Adult Nephrotic Syndrome: A Comparison of Renal Biopsy Findings from 1976-1979 and 1995-1997. American Journal of Kidney Diseases, 30, 621-631. http://dx.doi.org/10.1016/S0272-6386(97)90485-6

[14] Dragovic, D., Rosenstock, J.L., Wahl, S.J., Panagopoulos, G., Devita, M.V. and Michelis, M.F. (2005) Increasing Incidence of Focal Segmental Glomerulosclerosis and an Examination of Demographic Patterns. Clinical Nephrology, 63, 1-7. http://dx.doi.org/10.5414/CNP63001

[15] Jamal, Q., Jafarey, N.A. and Navi, A.J. (1988) A Review of 1508 Percutaneous Renal Biopsies. Journal of Pakistan Medical Association, 38, 272-275.

[16] Muzaffar, M., Mushtaq, S., Khadim, M.T., Nabiruddin and Mamoon, N. (1997) Morphological Pattern of Glomerular Diseases in Patients with Nephrotic Syndrome in Northern Pakistan. Pakistan Armed Forces Medical Journal, 47, 3-6.

[17] Osmani, M.H. and Frooqi, S. (2001) An Audit of Renal Biopsies. Journal of Surgery Pakistan, 6, 28-30.

[18] Khan, A.Z., Anwar, N., Munib, M. and Shah, F. (2004) Histological Pattern of Glomerulopathies at Khyber Teaching Hospital, Peshawar. Pakistan Journal of Medical Research, 43, 117-120.

[19] Kazi, J.I. and Mubarak, M. (2007) Pattern of Glomerulonephritides in Adult Nephritic Patients Report from SIUT (Letter to the Editor). Journal of Pakistan Medical Association, 57, 574.

[20] Zaffar, S.A. and Ali, A. (2008) Histological Pattern of Nephrotic Syndrome in Elderly Patients. Journal of Ayub Medical College Abbottabad, 20, 97-99.

[21] Mubarak, M., Kazi, J.I., Naqvi, R., Ahmed, E., Akhter, F., Naqvi, S.A. and Rizvi, S.A. (2011) Pattern of Renal Diseases Observed in Native Renal Biopsies in Adults in a Single Centre in Pakistan. Nephrology, 16, 87-92. http://dx.doi.org/10.1111/j.1440-1797.2010.01410.x

[22] Abbas, K., Mubarak, M., Kaziet, J.I. and Muzaffar, R. (2009) Pattern of Morphology in Renal Biopsies of Nephritic Syndrome Patients. Correlation with Immunoglobulin and Complement Deposition and Serology. Journal of Pakistan 
Medical Association, 59, 540-543.

[23] Sabir, S., Mubarak, M., Ul-Haq, I. and Bibi, A. (2013) Pattern of Biopsy Proven Renal Disease at PNS SHIFA Karachi: A Cross-Sectional Survey. Journal of Renal Injury Prevention, 2, 133-137.

[24] Choudhary, M., Masood, A., Rashid, F., Mand, A. and Nagi, A.H. (2014) Morphological Pattern of Glomerulonephritis in Males: A Multicenter Study. Biomedica, 30, 110-114. 